\title{
Centenário da Missão Parsons no Brasil (1921-2021)
}

\author{
Centenary of the Parsons Mission in Brazil (1921-2021) \\ Centenario de la Misión Parsons en Brasil (1921-2021)
}

Maria Angélica de Almeida Peres ${ }^{1}$ (C)

1. Universidade Federal do Rio de Janeiro, Escola de Enfermagem Anna Nery. Rio de Janeiro, RJ, Brasil.
Autor correspondente:

Maria Angélica de Almeida Peres.

E-mail: angelica.ufrj@uol.com.br

Recebido em 03/09/2021.

Aprovado em 06/09/2021.

DOI:https://doi.org/10.1590/2177-9465-EAN-2021-0349
Há uma gama de textos científicos que mencionam a Missão de Cooperação Técnica para o Desenvolvimento da Enfermagem no Brasil, ou Missão Parsons, como o marco fundamental para o reconhecimento da profissão da enfermagem no país. Foi em 02 de setembro de 1921 que a enfermeira Ethel Parsons aportou no Rio de Janeiro. Sua vinda foi resultado de uma parceria entre o Departamento Nacional de Saúde Pública (DNSP) do Brasil e a Fundação Rockefeller (FR) dos Estados Unidos, à época aliada ao governo norteamericano na implantação de programas voltados à formação e à pesquisa em saúde ${ }^{1,2}$.

A preocupação do governo brasileiro, tendo à frente o sanitarista Carlos Chagas, então diretor do DNSP, nomeado em 1920 pelo presidente Epitácio Pessoa, era conduzir uma reforma sanitária e fazer frente aos problemas de precariedade na vida e saúde da população brasileira. Foi com esse intuito que o DNSP reconheceu a propriedade da vinda da Missão Parsons e de sua finalidade ao implantar o Serviço de Enfermeiras de Saúde Pública e a Escola de Enfermeiras do DNSP, ambos criados em 1922.

Neste editorial, ressalta-se o significado do centenário da vinda de Ethel Parsons, enfermeira de saúde pública, membro especial da Internacional Health Board da FR, liderando a Missão, ao tempo em que nós, brasileiros, ratificamos a importância desse acontecimento como um dos definidores dos rumos da história da enfermagem brasileira. O perfil de Ethel Parsons, que, em seu país de origem, tinha assumido cargos como de Superintendente de Enfermagem do Departamento de Saúde de San Antonio/Texas e de Diretora de Enfermagem de Saúde Pública da Cruz Vermelha Americana,$^{3}$ inspirou a confiança de brasileiros, de tal modo que foi nomeada superintendente do primeiro Serviço de Enfermeiras de caráter público e de abrangência nacional, onde acumulou poderes políticos para a gestão, ensino e assistência de enfermagem.

Ethel Parsons atesta, em seu primeiro relatório, a real situação da enfermagem no país, destacando a inexistência de escola de formação de enfermeiras para vir a responder diante das necessidades de cuidado de enfermagem diagnosticadas naquela ocasião. Frente ao cenário que encontrou na capital brasileira, Ethel Parsons se posicionou em favor da formação de mulheres como enfermeiras dentro do padrão já pensado por enfermeiras norteamericanas e canadenses no Standard Curriculum for Nursing Schools, visando à formação de profissionais competentes para o desafio a ser enfrentado em nosso país.

A principal característica na liderança da Missão, percebida nos indícios da história, foi, sem dúvida, a capacidade de organização, que fez com que a própria Missão superasse a expectativa de alguns médicos brasileiros em relação ao perfil de enfermeira que seria possível ser formada no Brasil. Ao iniciar seus trabalhos frente à Missão e ao Serviço de Enfermeiras do DNSP, Ethel Parsons previu a necessidade de investimento na educação formal de enfermeiras e na imediata inserção delas nos serviços de saúde pública e hospitalar, levando à criação e organização de uma muito especial escola pública de formação de enfermeiras no país..$^{2,4}$

Nessas circunstâncias, os primeiros trabalhos da Missão Parsons incluíram a ação partícipe na reforma sanitária pela atuação nas Inspetorias de Saúde e supervisionando as visitas domiciliares que já eram realizadas por visitadoras. Essa intervenção das enfermeiras norte-americanas como Missão Parsons nas Inspetorias, por si só, veio assegurar uma reconfiguração hierárquica em todo o campo da saúde pública, compondo, em todo Brasil, a explicitação de um dos primeiros toques de qualidade, sobremodo, quando um alerta foi dado, de que as visitadoras trabalhariam somente sob supervisão de uma enfermeira diplomada, a qual já estava substituindo nesse trabalho, sob coordenação de Ethel Parsons, o médico chefe da Inspetoria ${ }^{4,5}$.

A presença de Ethel Parsons e das demais enfermeiras por ela selecionadas para integrar a Missão representou a inserção de profissionais, exclusivamente mulheres, em um 
ambiente masculino, onde ainda não havia liderança feminina relacionada às atividades de saúde. Embora tenha havido a formação de enfermeiros por outros cursos e escolas no Brasil, a Missão Parsons se preocupou principalmente em implantar e expandir no país as bases de ensino e formação instituídas por ideias nightingaleanas, como nos Estados Unidos, originando o modelo anglo-americano de enfermagem, conforme registrado por pesquisadoras brasileiras $2,4,5$.

Mesmo enfrentando grandes diferenças sociais entre o Brasi e os Estados Unidos, particularmente no que diz respeito ao papel da mulher na sociedade, Ethel Parsons prosseguiu com o desenvolvimento da enfermagem moderna no Brasil, confiante na transformação pela estruturação da educação acadêmicoprofissional, em bases curriculares sólidas e de nível superior, mesmo a Escola não sendo criada imediatamente na universidade.

Por todos os feitos da Missão Parsons e, além disso, pelos rumos que fez tomar a enfermagem como profissão, este Centenário nos faz aplaudir a vinda da Missão Parsons ao Brasil dos anos 1920 e, muito especialmente, por ter elucidado como futuridade em seu relatório final, de 1931, a convicção de que a formação ofertada pelo Brasil correspondia à formação universitária, o que, por motivos político-sociais, só veio a ocorrer efetivamente em 1937.

A afirmativa de muitos estudiosos do tema de que a Missão Parsons foi responsável pela implantação da enfermagem moderna no Brasil com a criação da Escola de Enfermeiras do DNSP, hoje Escola de Enfermagem Anna Nery da Universidade Federal do
Rio de Janeiro, é sustentável até hoje, devido ao reconhecimento de um padrão de ensino de enfermeiras que determinou forte identidade profissional na primeira metade do século $X X$. Antes mesmo desse reconhecimento, a primeira associação de enfermeiras brasileiras, criada em 1926, ascendeu a um lugar no Conselho Internacional de Enfermeiros (ICN), trazendo reconhecimento internacional a esse padrão no ano de 1929.

Considerando que a Lei do Padrão Anna Nery vigorou de 1931 até 1949, este Centenário da Missão Parsons significa um justo preito de gratidão à existência da enfermeira Ethel Parsons, sua vinda ao Brasil e todo o trabalho por ela liderado.

\section{REFERÊNCIAS}

1. Kondorfer AP. A Fundação Rockefeller e a formação de quadros para a enfermagem (Brasil: 1917-1951). Nuevo Mundo-Mundos Nuevos. 2019; 1-15. https://doi.org/10.4000/nuevomundo.76226.

2. Peters AA, Peres MAA, D'Antonio P. Influences of the Anglo-American Teaching System in Brazil: contributions by the Parsons Mission (19211925). OJIN: Online J Issues Nurs. 2020;25(2):3-11. http://dx.doi. org/10.3912/OJIN.Vol25No02Man06.

3. Fundação Rockefeller. Ficha de Registro da História Pessoal de Ethel Parsons. Tarritown, Nova lorque: Fundação Rockefeller; 1921. Rockefeller Archive Center, Box 22- série 1, Jan.

4. Carvalho V. Enfermagem e história da enfermagem: aspectos epistemológicos destacados na construção do conhecimento profissional. Esc Anna Nery. 2007;11(3):500-8. http://dx.doi.org/10.1590/S141481452007000300016.

5. Peres MAA, Padilha MICS. Uniforme como signo de uma nova identidade de enfermeira no Brasil (1923-1931). Esc Anna Nery. 2014;18(1):11221. https://doi.org/10.5935/1414-8145.20140017. 